\title{
Cancer-Related Fatigue and Muscle Quality in Hodgkin's Lymphoma Survivors
}

Integrative Cancer Therapies

2018, Vol. 17(2) 299-305

(C) The Author(s) 2017

Reprints and permissions:

sagepub.com/journalsPermissions.nav

DOI: $10.1177 / 15347354177 / 2009$

journals.sagepub.com/home/ict

(S) SAGE

\author{
Filipe Dinato de Lima, MSc', Martim Bottaro, PhD', \\ Ritielli de Oliveira Valeriano, MSc', Lorena Cruz, MSc', \\ Claudio L. Battaglini, PhD, FACSM ${ }^{2}$, Carlos Alexandre Vieira, PhD $^{3}$, \\ and Ricardo Jacó de Oliveira, PhD'
}

\begin{abstract}
The purpose of this study was to compare fatigue, strength, body composition, muscle thickness, and muscle quality between Hodgkin's lymphoma survivors (HLS) and apparently healthy subjects matched by age, gender, and physical activity levels $(\mathrm{CON})$. Twelve HLS $(32.16 \pm 8.06)$ and $36 \mathrm{CON}(32.42 \pm 7.64)$ were enrolled in the study. Fatigue was assessed using the 20-item Multidimensional Fatigue Inventory, muscle strength using an isokinetic dynamometer, body composition using dual-energy $\mathrm{X}$-ray absorptiometry, and thickness and muscle quality using B-mode ultrasound. Differences between HLS and CON were analyzed using independent samples $t$ tests. No significant differences were observed between groups for any demographic characteristics: age $(P=.922)$, weight $(P=.943)$, height $(P=.5 \mathrm{II})$, body mass index $(P=.796)$, fat mass $(P=.688)$, fat-free mass $(P=.520)$, and percent body fat $(P=.446)$. No significant differences were observed for strength (peak torque; $P=.552)$, relative peak torque $(P=.200)$, muscle thickness $(P>.05)$ and muscle quality $(P>.05)$. However, self-perceived fatigue was significantly higher in HLS than in CON $(P=.009)$. It appears that when HLS are matched by age and physical activity levels to CON, no significant difference in body composition, muscle thickness, muscle quality, or strength is observed. Self-perceived fatigue, as predicted, is higher in HLS, which may have implications and should be considered when prescribing exercise training to this cancer population.
\end{abstract}

\section{Keywords}

cancer-related fatigue, physical activity, strength, muscle quality, Hodgkin's lymphoma survivors

Submitted December 14, 2016; revised March 27, 2017; accepted April 2, 2017

\section{Introduction}

Hodgkin's lymphoma (HL) has a well-established treatment and a high prevalence of survivorship. ${ }^{1,2}$ However, the pathology and the treatment induce several side effects after the end of therapy. ${ }^{2,3}$ Such side effects induced by cancer and its medical treatments are known to cause significant decrease in functional capacity due to negative metabolic, endocrine, physical, functional, and mental alterations, which significantly affect the health-related quality of life and functional capacity. ${ }^{4-6}$ Cancer-related fatigue (CRF) is the most commonly reported side effect in cancer patients. It is a multifactorial process that involves negative alterations in different physiological systems. This debilitating fatigue is often accompanied by reductions in overall physical activity that can lead to decrements on physical function (ie, loss of skeletal muscle tissue), cognitive impairment, depression, pain, among other negative effects. ${ }^{7-19}$
CRF is a well-established long-term side effect of breast cancer, ${ }^{10,20-23}$ lung cancer, ${ }^{13}$ colorectal cancer, ${ }^{24}$ and hematologic cancer ${ }^{22,25,26}$ that can affect survivors several years after treatment. This long-term and persistent side effect has been reported to reduce physical capacity of cancer survivors, negatively affecting their overall quality of life. ${ }^{8,10,16,19}$ CRF is characterized as a subjective sense of fatigue and exhaustion that is not relieved by rest. ${ }^{27}$ Thus, many studies have aimed to relate CRF to biochemical and inflammatory changes. Saligan et $\mathrm{al}^{12}$ showed a strong

\footnotetext{
'University of Brasília, Brasília, Brazil

${ }^{2}$ University of North Carolina at Chapel Hill, NC, USA

${ }^{3}$ Federal University of Goiás, Goiania, Brazil

Corresponding Author:

Filipe Dinato de Lima, University of Brasília, Campus Darcy Ribeiro, Asa Norte, Brasília 70658-35I, Brazil.

Email: fdinatolima@gmail.com
} 
relation between CRF and an increased release of interleukin (IL)-6, tumor necrosis factor- $\alpha$ (TNF- $\alpha$ ), and C-reactive protein. Additionally, the severity of CRF seems to relate to levels of IL-1, TNF- $\alpha,{ }^{13}$ hormonal changes, fatigue, and pain. ${ }^{14}$ Therefore, a complex sequence of events that includes hormonal, metabolic, inflammatory, and neural changes is believed to compose the complex and multifactorial process of fatigue development. These changes have been associated with loss of skeletal muscle tissue and strength. ${ }^{12-15,18}$

Loss of skeletal muscle tissue related to cancer is a syndrome that promotes a decrease in physical performance, functional capacity, and well-being, leading to an increased risk for the development of other comorbidities. ${ }^{7,28,29}$ The pathophysiology of muscle loss is characterized by the imbalance between protein synthesis and degradation. Both increase in muscle degradation and decrease in protein synthesis in cancer patients are believed to be induced by impairments in metabolic and molecular mechanisms, such as the absence of oxygen availability due to increase of hypoxia-induced factor (HIF $1 \alpha),{ }^{30,31}$ increase of serum level of tumor-released proteolysis-inducing factor (PIF), ${ }^{7,32,33}$ and mitochondrial dysfunction due to reactive oxygen species (ROS). ${ }^{34,35}$

Vermaete et $\mathrm{al}^{36}$ have reported that fatigue increases and muscle strength decreases only 5 weeks after treatment in Hodgkin's lymphoma survivors (HLS) and non-HLS. The increased self-perceived fatigue may be associated with the loss of muscle strength, physical inactivity, and deconditioning. ${ }^{36}$ Moreover, a possible difference in time effect between fatigue, loss of muscle tissue, and decrease of strength in HLS may be related to muscle quality changes due to treatment and pathology. ${ }^{37}$ According to Cadore et al, ${ }^{38}$ Fukumoto et al,${ }^{39}$ and Watanabe et al,${ }^{40}$ muscle quality represents the portion of contractile structures in skeletal muscle tissue and is related to strength in middle age and older adults. Muscle quality is a qualitative measure of muscle properties, regarding atrophy of muscle fibers, intramuscular fat, and the amount of extracellular water relative to muscle volume. Therefore, muscle quality seems to represent an important and significant determinant of strength, because it reflects the real functional capacity of muscle tissue. ${ }^{41,42}$

Whereas fatigue in cancer survivors seems to be dependent, at least partially, on neuromuscular and morphological factors ${ }^{12,15,18}$ due to strength and muscle quality decreases, these relationships have not been well established in HLS. Thus, the purpose of this study was to assess and compare the levels of self-perceived fatigue, strength, muscle thickness, and muscle quality in HLS to apparently healthy subjects matched by age, gender, and levels of physical activity. It was hypothesized that fatigue in HLS would be higher than fatigue in healthy subjects, while strength, muscle thickness, and muscle quality would be lower in HLS than in healthy subjects.

\section{Methods}

\section{Subjects}

Hodgkin's lymphoma survivors were volunteers recruited from public and private hospitals in Brasília. Healthy subjects were volunteers recruited from the university community, by word of mouth and advertisements on the Internet. All participants were informed of the purpose, procedures, and risks of the study design prior to signing an informed consent. All procedures were approved by the University Institutional Ethics Committee. A total of 12 HLS, aged between 19 and 46 years, and 36 control healthy subjects $(\mathrm{CON})$, matched by age, gender, and level of physical activity, were volunteers in this study. Patients were included in HLS if the following inclusion criteria were met: age-range 18 to 60 years and had completed anticancer treatments at least 6 months before experimental procedures. CON participants were selected based on similar age, absence of cancer diagnosis, and similar levels of physical activity assessed using the International Physical Activity Questionnaire. ${ }^{43}$ This questionnaire quantifies the energy spent in 1 day and classifies the volunteers in sedentary, low levels of physical activity, moderate levels of physical activity, and high levels of physical activity. Such classification was used to match HLS and $\mathrm{CON}$ in order to isolate the activity level as a factor that contributes to CRF. Participants on this study were excluded if diagnosed with hypertension; cardiovascular, metabolic, and/or neuroendocrine disease; and/or any orthopedic limitation. The matched design was held in a proportion of 3 apparently healthy participants for each HLS. Therefore, a survivor was compared to 3 healthy subjects with the same age, gender, and level of physical activity. Seventy-nine apparently healthy subjects performed the strength, muscle thickness, and muscle quality assessment. Twelve healthy subjects were excluded due to diseases and limitations provided in exclusion criteria. Thirty-one apparently healthy subjects did not comply with one or more matched design criteria.

\section{Experimental Procedures}

After signing the informed consent form, enrolled participants reported to the laboratory at University of Brasília for testing just once for approximately 120 minutes. Both HLS and $\mathrm{CON}$ performed the following tests and evaluations in the same sequence: (1) self-perceived fatigue, (2) anthropometric and body composition, (3) muscle thickness and muscle quality, and (4) strength. All evaluations were performed at the same period of the day (afternoon), by the same researcher, in a controlled temperature room, from January to March 2016. All participants were asked to follow pre-assessment guidelines before reporting to the laboratory, including avoiding physical exertion for at least 24 hours prior to the evaluations. 


\section{Self-Perceived Fatigue and Body Composition}

Self-perceived fatigue was measured through the 20-item Multidimensional Fatigue Inventory. This questionnaire was designed to assess different levels of fatigue between different subjects, groups, and/or different conditions, as well as various populations. ${ }^{44}$ Five dimensions comprise the questionnaire, which measures fatigue experienced in previous days: General Fatigue, Physical Fatigue, Reduced Activity, Reduced Motivation, and Mental Fatigue. Although only General Fatigue is used as a wide, global, and general indicator of self-perceived fatigue and CRF, all dimensions were assessed and reported. The score is calculated in a range of 4 to 20 points, with 4 being little fatigue and 20 the highest level of fatigue. Fat mass, fat free mass, and percent body fat were assessed by dual-energy X-ray absorptiometry using a Lunar unit, model Lunar Prodigy Pro (GE Lunar, Madison, WI). All analyses were performed using the software GE Medical Systems Lunar.

\section{Muscle Thickness}

Muscle thickness was measured using B-mode ultrasound (Philips, VMI, Brazil). A 7.5-MHz scanning probe was placed on the skin perpendicular to the tissue interface. The scanning probe was coated with a water-soluble transmission gel to provide acoustic contact without depressing the dermal surface. No additional pressure was applied to standardize the compression on the dermal surface. The muscle thickness images were determined in lower-body muscles including the rectus femoris and vastus intermedius. The measurement for rectus femoris was taken at $60 \%$ of the distance from the greater trochanter to the lateral epicondyle and $3 \mathrm{~cm}$ lateral to the midline of the anterior thigh. ${ }^{38,45}$ Vastus intermedius was measured at the rectus femoris. Once the examiner found a satisfactory image, it was frozen, stored, and analyzed using the software Image-J (version 1.49; National Institute of Health, Bethesda, MD). The distance between subcutaneous adipose tissue-rectus femoris interface and rectus femoris-vastus intermedius interface was designated as RF; the distance between subcutaneous adipose tissue-rectus femoris interface and vastus intermedius-bone interface was designated as RF + VI. All measurements and analyses were performed 3 times by the same researcher and the mean value was used for analysis.

\section{Muscle Quality}

Muscle quality was assessed by 2 different methods: (1) echo intensity (EI) of rectus femoris (RF) and (2) specific torque (ST). The EI was determined by gray-scale analysis using the standard histogram function Image-J. In order to assess muscle quality in the rectus femoris, a region of interest was selected in each muscle without any bone or surrounding fascia, with a depth limit of $5 \mathrm{~cm} .{ }^{38}$ When this setting proved insufficient to display the entire muscle, only the superficial part was used for analysis. A reliable measurement of EI is extracted from a minimum of $15 \%$ of muscle area. ${ }^{46}$ The EI was expressed in values between 0 (black) and 256 (white). The increase in EI value represents a decrease in muscle quality. ${ }^{39,40,42,46}$ The ST was defined as the force produced per unit of muscle tissue (ie, muscle thickness). The ST was calculated as follows: isokinetic peak torque/RF + vastus intermedius (VI). ${ }^{41,47}$

\section{Muscle Strength}

Isokinetic muscle strength (peak torque $[\mathrm{PT}]$ ) was measured using an isokinetic Biodex System 3 (Biodex Medical, Inc, Shirley NY) dynamometer. Subjects were positioned on the dynamometer seat with safety belts fastened to the trunk, pelvis, and thigh to avoid extraneous body movements that could affect PT values. The lateral epicondyle of the femur was used to align the knee rotation axis and the dynamometer rotation axis, allowing free knee extension and flexion from $85^{\circ}$ flexion to full extension. Gravity correction was obtained by measuring the torque exerted by the lever arm and the participant's leg at $30^{\circ}$ flexion as well as in a relaxed position. The values of the isokinetic variables were automatically adjusted for gravity with the software Biodex Advantage (Biodex Medical, Inc, Shirley NY). The calibration of dynamometer was carried out according to the specifications provided by the manufacture. For the test, participants were asked to cross their arms across their chest. ${ }^{48}$ The same researcher carried out the test procedures for all participants and provided verbal encouragement.

As part of familiarization with isokinetic knee extension and warm-up, subjects performed one set of 10 submaximal knee isokinetic extension at $120^{\circ} \mathrm{s}^{-1}$. Five minutes after familiarization/warmup session, volunteers performed 2 sets of 4 maximal isokinetic knee extension at $60^{\circ} \mathrm{s}^{-1} \cdot{ }^{49}$ The volunteers rested for 3 minutes between both sets because recent studies suggest that cancer survivors must rest more minutes than healthy subjects to sustain strength and total work in a strength training proto$\mathrm{col}^{48}$ After the isokinetic knee extension assessment, 2 variables were evaluated: PT and relative peak torque (RPT).

\section{Statistical Analysis}

Data are presented as mean \pm standard deviation. Normal distribution parameters were checked with Shapiro-Wilk test. To compare fatigue, physical characteristics, body composition, muscle quality, and strength variables independent samples $t$ tests were used. Cohen's $d$ was calculated for all variables, even nonsignificant ones, because it is not affected by sample size and estimates the magnitude of the difference according the following criteria: $<0.20$ small; 0.20 to 0.50 medium; 0.80 to 2.00 large. Analyses were performed in the statistical software SPSS, version 21.0. A $P$ value of $\leq .05$ was adopted for all analyses. 
Table I. Demographics and Clinical Characteristics of HLS.

\begin{tabular}{|c|c|c|}
\hline Clinical Characteristics & $\mathrm{HLS}(\mathrm{n}=12)$ & $\operatorname{CON}(n=36)$ \\
\hline Female sex, n (\%) & 7 (58.33\%) & $21(58.33 \%)$ \\
\hline \multicolumn{3}{|l|}{ Ethnicity, n (\%) } \\
\hline White & $3(25 \%)$ & $20(55.6 \%)$ \\
\hline Black & $4(33 \%)$ & I (2.8\%) \\
\hline Pardo & $5(42 \%)$ & $15(41.7 \%)$ \\
\hline Presence of B symptoms, n (\%) & $7(58.33 \%)$ & - \\
\hline \multicolumn{3}{|l|}{ First lymph node appearance, n (\%) } \\
\hline Mediastinum & $6(50 \%)$ & - \\
\hline Neck & $5(41.67 \%)$ & - \\
\hline Groin & I (8.33\%) & - \\
\hline Sessions of CT (mean \pm SD) & $11.80 \pm 4.66$ & - \\
\hline Sessions of RT (mean \pm SD) & $12.00 \pm 10.79$ & - \\
\hline Years from diagnosis (mean $\pm S D$ ) & $4.80 \pm 3.54$ & - \\
\hline Age at diagnosis (mean $\pm S D)$ & $26.50 \pm 6.31$ & - \\
\hline \multicolumn{3}{|l|}{ Level of physical activity, n (\%) } \\
\hline Low levels & $2(16.67 \%)$ & $6(16.67 \%)$ \\
\hline Moderate levels & $3(25 \%)$ & $9(25 \%)$ \\
\hline High levels & 7 (58.33\%) & $21(58.33 \%)$ \\
\hline
\end{tabular}

Abbreviations: HLS, Hodgkin's lymphoma survivors; CON, control group;

$\mathrm{SD}$, standard deviation; CT, chemotherapy; RT, radiotherapy.

Table 2. Descriptive and Comparative Data in HLS and CON ${ }^{\mathrm{a}}$.

\begin{tabular}{lccc}
\hline Variable & HLS $(\mathrm{n}=12)$ & CON $(\mathrm{n}=36)$ & $P$ \\
\hline Age (years) & $32.16 \pm 8.06$ & $32.42 \pm 7.64$ & .922 \\
Weight $(\mathrm{kg})$ & $72.59 \pm 9.83$ & $72.25 \pm 15.10$ & .943 \\
Height $(\mathrm{m})$ & $1.70 \pm 0.08$ & $1.68 \pm 0.09$ & .511 \\
BMI $\left(\mathrm{kg} \mathrm{m}^{-2}\right)$ & $25.22 \pm 2.71$ & $25.54 \pm 3.94$ & .796 \\
FM $(\mathrm{kg})$ & $25.45 \pm 8.84$ & $24.19 \pm 9.47$ & .688 \\
FFM $(\mathrm{kg})$ & $42.88 \pm 11.34$ & $44.54 \pm 10.59$ & .520 \\
PBF $(\%)$ & $37.42 \pm 12.32$ & $34.73 \pm 9.87$ & .446 \\
\hline
\end{tabular}

Abbreviations: HLS, Hodgkin's lymphoma survivors; CON, control group; BMI, body mass index; FM, fat mass; FFM, fat-free mass; PBF, percent body fat.

${ }^{\text {aDData }}$ are presented as mean \pm standard deviation.

\section{Results}

Twelve HLS (5 men and 7 women) composed the HLS group and 36 apparently healthy participants $(15$ men and 21 women) composed the CON group. HLS clinical characteristics are reported in Table 1.

Descriptive and comparative data analysis of HLS and $\mathrm{CON}$ are reported in Table 2. No significant differences in any physical characteristics between HLS and CON were observed.

Strength, muscle thickness, muscle quality, and fatigue variables are presented in Table 3. There was no difference in strength parameters (PT, RPT), muscle thickness, or muscle quality (EI and ST) between HLS and CON. However, there was a significant difference between HLS and CON in general fatigue with HLS presenting significantly higher fatigue levels than CON $(P=.009)$. There was no difference between HLS and CON in physical fatigue, reduced activity, reduced motivation, and mental fatigue. Cohen's $d$ coefficient in general
Table 3. Strength, Muscle Thickness, Muscle Quality, and Self-Perceived Fatigue in HLS and CON ${ }^{\mathrm{a}}$.

\begin{tabular}{lcccc}
\hline Variable & HLS $(n=12)$ & CON $(n=36)$ & $P$ & $\begin{array}{c}\text { Effect } \\
\text { size }\end{array}$ \\
\hline PT $(\mathrm{Nm})$ & $184.58 \pm 55.91$ & $199.14 \pm 60.57$ & .552 & 0.25 \\
RPT $(\%)$ & $250.39 \pm 60.07$ & $275.72 \pm 57.88$ & .200 & 0.43 \\
RF $(\mathrm{mm})$ & $13.10 \pm 4.28$ & $13.64 \pm 4.41$ & .716 & 0.12 \\
RF + VI $(\mathrm{mm})$ & $27.35 \pm 8.70$ & $28.55 \pm 7.58$ & .439 & 0.15 \\
EIRF & $63.18 \pm 11.12$ & $65.36 \pm 11.76$ & .575 & 0.19 \\
ST $\left.(\mathrm{Nm} \mathrm{mm})^{-1}\right)$ & $6.89 \pm 1.59$ & $7.05 \pm 1.46$ & .737 & 0.10 \\
General Fatigue & $14.00 \pm 3.91$ & $10.80 \pm 3.36$ & .009 & 0.88 \\
Physical Fatigue & $11.25 \pm 4.33$ & $10.61 \pm 3.80$ & .654 & 0.16 \\
Reduced Activity & $10.17 \pm 3.95$ & $8.31 \pm 3.00$ & .155 & 0.53 \\
Reduced Motivation & $7.25 \pm 3.02$ & $7.06 \pm 2.95$ & .848 & 0.06 \\
Mental Fatigue & $12.25 \pm 3.98$ & $9.56 \pm 3.89$ & .051 & 0.68 \\
\hline
\end{tabular}

Abbreviations: HLS, Hodgkin's lymphoma survivors; CON, control group; PT, peak torque; RPT, relative peak torque; RF, muscle thickness of rectus femoris; $\mathrm{RF}+\mathrm{VI}$, muscle thickness of rectus femoris and vastus intermedius; EIRF, echo intensity of rectus femoris; ST, specific torque.

${ }^{a}$ Data are presented as mean \pm standard deviation.

fatigue level showed a large difference between HLS and CON by age, gender, and level of physical activity. Cohen's $d$ coefficient in PT, RPT, reduced activity, and mental fatigue showed a moderate difference between HLS and CON. Cohen's $d$ coefficient in muscle thickness, muscle quality, physical fatigue, and reduced motivation showed a small difference between HLS and CON.

\section{Discussion}

The purpose of this study was to assess fatigue, strength, muscle thickness, and muscle quality in HLS and to compare these variables with apparently healthy participants $(\mathrm{CON})$ matched by age, gender, and level of physical activity. As hypothesized, significantly different levels of self-perceived fatigue were observed between HLS and CON; however, and very surprising, no differences in strength, muscle thickness, and muscle quality were observed between groups.

A debilitating state of self-perceived fatigue, named cancer-related fatigue, has been well established in breast cancer, lung cancer, colorectal cancer, and hematological cancer survivors. ${ }^{10,12,13,20-26}$ Such side effect affects $74 \%$ to $96 \%$ of cancer survivors. ${ }^{25,50}$ Etiology and pathophysiology of CRF is still unknown and controversial, despite all efforts to relate this late and persistent symptom to biochemistry, neuroendocrine, and/or morphological changes. According to Saligan et al, ${ }^{12} \mathrm{CRF}$ is a consequence of inflammatory dysfunctions, neuroendocrine and metabolic impairment, and mitochondrial death, due to the release of reactive oxygen species caused by the cytotoxic nature of cancer treatments. This sequence of events promotes permanent and transitory changes that contribute to fatigue, including anemia, loss of skeletal muscle tissue, infections, and metabolic disorders. ${ }^{51}$

Chemotherapy is one of the most relevant causes of increased fatigue due to an inflammatory imbalance and also 
to an increase in cytokine release. ${ }^{13}$ In fact, chemotherapy promotes various malignacies, affecting the gastrointestinal tract, hematological profiles, cardiovascular and neural toxicities, which lead to several physiological impairments contributing to the development of a debilitating state of fatigue. ${ }^{15}$ Additionally, Cleeland et $\mathrm{al}^{6}$ propose that symptoms related to fatigue are caused by pathology and treatment similarly, through the same physiological mechanisms, including increase in cytokine release and impairment in central and peripheral nervous system. Peripheral and central fatigue contribute to decrements in muscle performance and impairments in nervous systems activation pathways that may be caused by the same mechanism: hypothalamicpituitary-adrenal axis disruption, serotonin dysregulation, growth-factor activation, and circadian rhythm dysfunction, along with metabolic changes and increased systemic acidity (ie, Warburg effect, mitochondrial dysfunction, and impairments of oxidative energy metabolism). ${ }^{15,52-55}$

Reductions in level of physical activity is strongly proposed as a cause of CRF due to its influence on loss of skeletal muscle tissue, reduction of strength, and functional impairment. ${ }^{11,14,18}$ Saligan et al $^{12}$ suggest that CRF, physical inactivity, motor and neural impairment, muscle loss, and psychological dysfunctions occur cyclically and persistently, promoting a vicious circle of symptoms. However, even though our results showed higher levels of fatigue in HLS when compared with CON, no difference in strength, muscle thickness, and muscle quality was observed between groups. These results may be explained mostly by the matched levels of physical activity and age implied in the study design as an attempt to provide more precise interpretations on the physiological differences as well as on the physical performance tests used to characterize this group of HLS. ${ }^{12,56}$ Otherwise, loss of skeletal muscle tissue, reductions of strength, and CRF may be caused by similar physiological impairments but are not directly related, since muscle strength seems not to strongly affect self-perceived fatigue. ${ }^{57}$

Cancers survivors commonly report high levels of selfperceived fatigue and tend to perform at lower levels on physical and functional performance tests when compared with individuals with similar age and similar fitness levels who had never been treated for cancer. This phenomenon suggests, at least in part, that the multifactorial nature of fatigue development in cancer patients does in fact affect survivors exercise tolerability. ${ }^{27}$ However, the results of the current study suggest that HLS may experience an increased self-perceived fatigue regardless of their strength and muscle function characteristics. In fact, CRF may be a consequence of metabolic changes, Warburg effect, increased release of reactive oxygen species, mitochondrial dysfunctions, and acid-base imbalance ${ }^{12,13,15,31,58}$ and/or inflammatory changes and increased cytokine release ${ }^{12}$; and/or neuroendocrine changes ${ }^{14,59}$; and/or central nervous system changes and impairments that seems to be alleviated as survivors are further out from the completion of their major cancer treatments. ${ }^{60}$ In a recent and relevant review about fatigue, Enoka and Duchateau ${ }^{61}$ suggest that fatigue should be divided into 2 attributes: performance fatigability, defined as the decline in an objective measure of performance over a discrete period of time; and perceived fatigability, defined as changes in the sensations that regulate the integrity of the performer.

In contrast to our hypothesis, where we did not find any differences in strength, muscle thickness, and muscle quality between HLS and CON matched by age, gender, and level of physical activity, muscle strength decrease in HLS during the initial 5 weeks after treatment, independently of physical activity level, has been documented and attributed to decline in muscle synthesis associated with chemotherapy agents. ${ }^{36}$ Therefore, the relationship between increased fatigue perception, decreased muscle strength, and physical inactivity proposed by Vermaete et $\mathrm{al}^{36}$ may change over time. In the current study, the members of the HLS group had completed their major cancer treatment at least 6 months previously. Furthermore, even the lower levels of physical activity in the HLS group showed no difference in any muscle characteristics or muscle performance tests, leading us to believe that time of treatment may be a determinant factor of improving exercise tolerability.

To our knowledge, this was the first study that assessed muscle thickness and muscle quality in HLS. The absence of difference between HLS and CON was different from other pathologies with muscle strength decrease ${ }^{62}$ and metabolic impairments. ${ }^{63}$ Apparently, an increase in intramuscular fat infiltration observed in chronic obstructive pulmonary disease and type 2 diabetes did not occur in HLS who participated in the current study in contrast with previous studies. ${ }^{7,37}$

An important limitation of this cross-sectional study was the small size of the sample. We experienced some difficulties in recruiting and including HLS due to the low prevalence of Hodgkin's disease in comparison with other types of cancers. In order to reduce the small sample size relevance and the risk of an underpowered data, effect size was calculated for all variables and confirms the statistical results. It is also important to note that this preliminary study provides insight on the potential similarities between HLS and CON regarding muscle characteristics, function, and performance, so exercise specialists can more confidently prescribe resistance exercise, knowing that the muscle characteristics appears to follow the same capacities as of individuals of similar age, gender, and physical activity levels who have never been diagnosed with Hodgkin's lymphoma, nor undergone anticancer treatments. Evidently, these statements above are simply a speculation at this time and more research is needed to confirm or refute these possibilities. This study should be seen as a hypothesis-generating study, providing initial information about fatigue mechanisms unrelated to strength, muscle thickness, and muscle quality. For future research, it is recommended that a larger sample size, other cancer types, and different fatigue assessments be considered for methodological designs. 


\section{Conclusion}

In summary, as hypothesized, a higher level of self-perceived fatigue was observed in HLS when compared to CON. Contrary to what our team had hypothesized, no differences in muscle strength, muscle thickness, and muscle quality were observed when HLS are matched by age, gender, and physical activity level with CON. It appears that as HLS are further out from the completion of their major anticancer treatments, their muscle characteristics and function appears to return to precancer levels as witnessed by the comparisons made in the current study against age, gender, and physical activity levels matched CON participants. Once again, self-perceived fatigue, as consistently reported in the literature as the most commonly diagnosed side effect of cancer and cancer treatments, may also last months and even years after completion of treatments in HLS. Further investigations are paramount in order to discover if new strategies, such as exercise, can become more specific in alleviating or even reversing this debilitating side effect that significantly affect the quality of life of cancer patients.

\section{Declaration of Conflicting Interests}

The author(s) declared no potential conflicts of interest with respect to the research, authorship, and/or publication of this article.

\section{Funding}

The author(s) received no financial support for the research, authorship, and/or publication of this article.

\section{References}

1. Canellos GP, Anderson JR, Propert KJ, et al. Chemotherapy of advanced Hodgkin's disease with MOPP, ABVD, or MOPP alternating with ABVD. N Engl J Med. 1992;327:1478-1484.

2. Canellos GP, Niedzwiecki D. Long-term follow-up of Hodgkin's disease trial. N Engl J Med. 2002;346:1417-1418.

3. Hodgson DC. Hodgkin lymphoma: the follow-up of long-term survivors. Hematol Oncol Clin North Am. 2008;22:233-244.

4. Heidenreich PA, Hancock SL, Lee BK, Mariscal CS, Schnittger I. Asymptomatic cardiac disease following mediastinal irradiation. J Am Coll Cardiol. 2003;42:743-749.

5. Tarlaci S. Vincristine-induced fatal neuropathy in non-Hodgkin's lymphoma. Neurotoxicology. 2008;29:748-749.

6. Cleeland CS, Bennett GJ, Dantzer R, et al. Are the symptoms of cancer and cancer treatment due to a shared biologic mechanism? A cytokine-immunologic model of cancer symptoms. Cancer. 2003;97:2919-2925.

7. Al-Majid S, Waters H. The biological mechanisms of cancerrelated skeletal muscle wasting: the role of progressive resistance exercise. Biol Res Nurs. 2008;10:7-20.

8. Diaz N, Menjon S, Rolfo C, et al. Patients' perception of cancer-related fatigue: results of a survey to assess the impact on their everyday life. Clin Transl Oncol. 2008;10:753-757.

9. Hartman A, van den Bos C, Stijnen T, Pieters R. Decrease in peripheral muscle strength and ankle dorsiflexion as longterm side effects of treatment for childhood cancer. Pediatr Blood Cancer. 2008;50:833-837.
10. Kluthcovsky AC, Urbanetz AA. Fatigue and quality of life in breast cancer survivors: a comparative study. Rev Bras Ginecol Obstet. 2015;37:119-126.

11. Neil-Sztramko SE, Kirkham AA, Hung SH, Niksirat N, Nishikawa K, Campbell KL. Aerobic capacity and upper limb strength are reduced in women diagnosed with breast cancer: a systematic review. J Physiother. 2014;60:189-200.

12. Saligan LN, Olson K, Filler K, et al. The biology of cancer-related fatigue: a review of the literature. Support Care Cancer. 2015;23:2461-2478.

13. Sha F, Zhuang S, Zhou L, et al. Biomarkers for cancer-related fatigue and adverse reactions to chemotherapy in lung cancer patients. Mol Clin Oncol. 2015;3:163-166.

14. Thornton LM, Andersen BL, Blakely WP. The pain, depression, and fatigue symptom cluster in advanced breast cancer: covariation with the hypothalamic-pituitary-adrenal axis and the sympathetic nervous system. Health Psychol. 2010;29:333-337.

15. Wang XS, Woodruff JF. Cancer-related and treatment-related fatigue. Gynecol Oncol. 2015;136:446-452.

16. Wang XS, Zhao F, Fisch MJ, et al. Prevalence and characteristics of moderate-to-severe fatigue: a multicenter study in cancer patients and survivors. Cancer. 2014;120:425-432.

17. Zebrack BJ, Zeltzer LK, Whitton J, et al. Psychological outcomes in long-term survivors of childhood leukemia, Hodgkin's disease, and non-Hodgkin's lymphoma: a report from the Childhood Cancer Survivor Study. Pediatrics. 2002;110(1 Pt 1):42-52.

18. Berger AM, Gerber LH, Mayer DK. Cancer-related fatigue: implications for breast cancer survivors. Cancer. 2012;118(8 suppl):2261-2269.

19. McCabe RM, Grutsch JF, Braun DP, Nutakki SB. Fatigue as a driver of overall quality of life in cancer patients. PLoS One. 2015; 10:e0130023.

20. Bodtcher H, Bidstrup PE, Andersen I, et al. Fatigue trajectories during the first 8 months after breast cancer diagnosis. Qual Life Res. 2015;24:2671-2679.

21. Broeckel JA, Jacobsen PB, Horton J, Balducci L, Lyman GH. Characteristics and correlates of fatigue after adjuvant chemotherapy for breast cancer. J Clin Oncol. 1998;16:1689-1696.

22. Ganz PA, Bower JE. Cancer related fatigue: a focus on breast cancer and Hodgkin's disease survivors. Acta Oncol. 2007;46:474-479.

23. Meneses-Echávez JF, González-Jiménez E, Ramírez-Vélez $R$. Effects of supervised exercise on cancer-related fatigue in breast cancer survivors: a systematic review and meta-analysis. BMC Cancer. 2015;15:77.

24. Li SX, Liu BB, Lu JH. Longitudinal study of cancer-related fatigue in patients with colorectal cancer. Asian Pac J Cancer Prev. 2014;15:3029-3033.

25. Wang XS, Giralt SA, Mendoza TR, et al. Clinical factors associated with cancer-related fatigue in patients being treated for leukemia and non-Hodgkin's lymphoma. J Clin Oncol. 2002;20:1319-1328.

26. Musarezaie A, Khaledi F, Esfahani HN, Ghaleghasemi TM. Factors affecting quality of life and fatigue in patients with leukemia under chemotherapy. J Educ Health Promot. 2014;3:64.

27. Bennett B, Goldstein D, Lloyd A, Davenport T, Hickie I. Fatigue and psychological distress: exploring the relationship in women treated for breast cancer. Eur J Cancer. 2004:40:1689-1695. 
28. Stewart GD, Skipworth RJ, Fearon KC. Cancer cachexia and fatigue. Clin Med (Lond). 2006;6:140-143.

29. Stene GB, Helbostad JL, Balstad TR, Riphagen II, Kaasa S, Oldervoll LM. Effect of physical exercise on muscle mass and strength in cancer patients during treatment: a systematic review. Crit Rev Oncol Hematol. 2013;88:573-593.

30. Marin-Hernandez A, Gallardo-Perez JC, Ralph SJ, RodriguezEnriquez S, Moreno-Sanchez R. HIF-1alpha modulates energy metabolism in cancer cells by inducing over-expression of specific glycolytic isoforms. Mini Rev Med Chem. 2009;9:1084-1101.

31. Swietach P, Vaughan-Jones RD, Harris AL, Hulikova A. The chemistry, physiology and pathology of $\mathrm{pH}$ in cancer. Philos Trans R Soc Lond B Biol Sci. 2014;369:20130099.

32. Costelli P, Reffo P, Penna F, Autelli R, Bonelli G, Baccino FM. $\mathrm{Ca}(2+)$-dependent proteolysis in muscle wasting. Int $J$ Biochem Cell Biol. 2005;37:2134-2146.

33. Eley HL, Russell ST, Tisdale MJ. Effect of branched-chain amino acids on muscle atrophy in cancer cachexia. Biochem J. 2007;407:113-120.

34. Ansell SM. Hodgkin lymphoma: 2012 update on diagnosis, risk-stratification, and management. Am J Hematol. 2012;87:1096-1103.

35. McLean JB, Moylan JS, Andrade FH. Mitochondria dysfunction in lung cancer-induced muscle wasting in $\mathrm{C} 2 \mathrm{C} 12$ myotubes. Front Physiol. 2014;5:503.

36. Vermaete N, Wolter P, Verhoef G, Gosselink R. Physical activity and physical fitness in lymphoma patients before, during, and after chemotherapy: a prospective longitudinal study. Ann Hematol. 2014;93:411-424.

37. Gorselink M, Vaessen SF, van der Flier LG, et al. Massdependent decline of skeletal muscle function in cancer cachexia. Muscle Nerve. 2006;33:691-693.

38. Cadore EL, Izquierdo M, Conceicao M, et al. Echo intensity is associated with skeletal muscle power and cardiovascular performance in elderly men. Exp Gerontol. 2012;47:473-478.

39. Fukumoto Y, Ikezoe T, Yamada Y, et al. Skeletal muscle quality assessed from echo intensity is associated with muscle strength of middle-aged and elderly persons. Eur J Appl Physiol. 2012;112:1519-1525.

40. Watanabe Y, Yamada Y, Fukumoto Y, et al. Echo intensity obtained from ultrasonography images reflecting muscle strength in elderly men. Clin Interv Aging. 2013;8:993-998.

41. Radaelli R, Neto W, Nestor E, Marques MFB, Pinto RS. Muscle thickness and muscle quality measured by ultrasound: influence of different sites of measurement. Revista Brasileira de Cineantropometria \& Desempenho Humano. 2011;13:87-93.

42. Rech A, Radaelli R, Goltz FR, da Rosa LH, Schneider $\mathrm{CD}$, Pinto RS. Echo intensity is negatively associated with functional capacity in older women. Age (Dordr). 2014; 36:9708.

43. Benedetti TRB, Antunes PdC, Rodriguez-Añez CR, Mazo GZ, Petroski ÉL. Reprodutibilidade e validade do Questionário Internacional de Atividade Física (IPAQ) em homens idosos. Revista Brasileira de Medicina do Esporte. 2007;13:11-16.

44. Smets EM, Garssen B, Bonke B, De Haes JC. The Multidimensional Fatigue Inventory (MFI) psychometric qualities of an instrument to assess fatigue. J Psychosom Res. 1995;39:315-325.
45. Chilibeck PD, Stride D, Farthing JP, Burke DG. Effect of creatine ingestion after exercise on muscle thickness in males and females. Med Sci Sports Exerc. 2004;36:1781-1788.

46. Caresio C, Molinari F, Emanuel G, Minetto MA. Muscle echo intensity: reliability and conditioning factors. Clin Physiol Funct Imaging. 2015;35:393-403.

47. Gauche R, Gadelha AB, Paiva FML, Oliveira PFAd, Lima RM. Strength, muscle quality and markers of cardiometabolic risk in older women. Revista Brasileira de Cineantropometria \& Desempenho Humano. 2015;17:186-194.

48. Vieira CA, Battaglini CL, Ferreira-Junior JB, et al. Effects of rest interval on strength recovery in breast cancer survivors. Int J Sports Med. 2015;36:573-578.

49. Bottaro M, Russo Aé F, de Oliveira R. The effects of rest interval on quadriceps torque during an isokinetic testing protocol in elderly. J Sports Sci Med. 2005;4:285-290.

50. Portenoy RK, Itri LM. Cancer-related fatigue: guidelines for evaluation and management. Oncologist. 1999;4:1-10.

51. Gutstein HB. The biologic basis of fatigue. Cancer. 2001;92(6 suppl):1678-1683.

52. Barsevick A, Frost M, Zwinderman A, Hall P, Halyard M. I'm so tired: biological and genetic mechanisms of cancerrelated fatigue. Qual Life Res. 2010;19:1419-1427.

53. Ryan JL, Carroll JK, Ryan EP, Mustian KM, Fiscella $\mathrm{K}$, Morrow GR. Mechanisms of cancer-related fatigue. Oncologist. 2007;12(suppl 1):22-34.

54. Evans ES, Battaglini CL, Groff DG, Hackney AC. Aerobic exercise intensity in breast cancer patients: a preliminary investigation. Integr Cancer Ther. 2009;8:139-147.

55. Tosti KP, Hackney AC, Battaglini CL, Evans ES, Groff D. Exercise in patients with breast cancer and healthy controls: energy substrate oxidation and blood lactate responses. Integr Cancer Ther. 2011;10:6-15.

56. Oldervoll LM, Kaasa S, Knobel H, Loge JH. Exercise reduces fatigue in chronic fatigued Hodgkin's disease survivors: results from a pilot study. Eur J Cancer. 2003;39:57-63.

57. Schvartsman G, Park M, Liu DD, Yennu S, Bruera E, Hui D. Could objective tests be used to measure fatigue in patients with advanced cancer? [published online January 4, 2017]. J Pain Symptom Manage. doi:10.1016/j.jpainsymman.2016.12.343.

58. Carroll JK, Kohli S, Mustian KM, Roscoe JA, Morrow GR. Pharmacologic treatment of cancer-related fatigue. Oncologist. 2007;12(suppl 1):43-51.

59. Schmidt ME, Semik J, Habermann N, Wiskemann J, Ulrich CM, Steindorf K. Cancer-related fatigue shows a stable association with diurnal cortisol dysregulation in breast cancer patients. Brain Behav Immun. 2016;52:98-105.

60. Rovigatti U. Chronic fatigue syndrome (CFS) and cancer related fatigue (CRF): two "fatigue" syndromes with overlapping symptoms and possibly related aetiologies. Neuromuscul Disord. 2012;22(suppl 3):S235-S241.

61. Enoka RM, Duchateau J. Translating fatigue to human performance. Med Sci Sports Exerc. 2016;48:2228-2238.

62. Robles PG, Sussman MS, Naraghi A, et al. Intramuscular fat infiltration contributes to impaired muscle function in COPD. Med Sci Sports Exerc. 2015;47:1334-1341.

63. Park SW, Goodpaster BH, Strotmeyer ES, et al. Decreased muscle strength and quality in older adults with type 2 diabetes: the health, aging, and body composition study. Diabetes. 2006;55:1813-1818. 